\section{Juan F. Navarro ${ }^{\text {a }}$}

José L. Teruel ${ }^{\mathrm{b}}$

a Hospital Nuestra Señora de Candelaria, Tenerife, and

${ }^{b}$ Department of Nephrology, Hospital

Ramón y Cajal, Madrid, Spain

Dear Sir,

Over the last few years, the use of calcium salts has become an alternative method to phosphate binders containing aluminum in the control of hyperphosphatemia in dialysis patients, hypercalcemia being the main limitation to this therapeutical approach [1]. On this basis, a reduction in the calcium dialysate $(\mathrm{CD})$ concentration has been proposed in order to prevent the appearance of hypercalcemia [2, 3]. However, the use of low $\mathrm{CD}$ concentrations may have negative effects on cardiovascular stability during hemodialysis (HD) [4, 5].

In a recent study, Fabrizi et al. [6] examined the acute clinical consequences of lower $\mathrm{CD}$ levels. They found that the percent reduction in blood pressure (BP) after HD sessions was significantly greater with low CD (2.5 $\mathrm{mEq} / \mathrm{l})$ than with standard $\mathrm{CD}(3.5 \mathrm{mEq} / \mathrm{l})$, and concluded that an optimal BP control and intradialytic tolerance can be achieved in chronic HD with a reduced calcium dialysate concentration, although the results show that cardiovascular stability is better with a $\mathrm{CD}$ concentration of $3.5 \mathrm{mEq} / 1$.

Recently, we reported our experience after 1 year of using a low CD [7] in HD patients not receiving vitamin $\mathrm{D}$. We reduced the dialysis fluid calcium level in 26 patients on maintenance HD with standard $\mathrm{CD}$, and gradually increased the oral dose of calcium carbonate and reduced the dose of aluminum hydroxide to maintain the serum calcium and phosphate levels in the adequate range. Thus, after 1 year of HD with a low $\mathrm{CD}$, the dose of calcium carbonate increased from $3.5 \pm 2.6$ to $9.2 \pm 5.6 \mathrm{~g} /$ day $(\mathrm{p}<0.001)$. In order to evaluate the tolerance to low $\mathrm{CD}$, we measured $\mathrm{BP}$ before and after dialysis, and controlled the hypotensive episodes and cramps during the HD sessions 3 months before lowering the $\mathrm{CD}$ level and compared the results with those during the first 3 months of the study. The tolerance to

\title{
Intradialytic Cardiovascular Stability with Low Calcium Dialysate Levels
}

Table 1. Systolic and diastolic blood pressure (SBP and DBP), and prevalence of hypotensive episodes and cramps during hemodialysis (HD) with standard and low calcium dialysate (CD)

\begin{tabular}{lccc}
\hline & Standard CD & Low CD & $\mathrm{p}$ \\
\hline Pre-HD SBP, mm Hg & $143 \pm 20$ & $144 \pm 9$ & NS \\
Post-HD SBP, mm Hg & $124 \pm 21$ & $123 \pm 15$ & NS \\
Pre-HD DBP, mm Hg & $80 \pm 9$ & $79 \pm 10$ & NS \\
Post-HD DBP, mm Hg & $72 \pm 12$ & $72 \pm 8$ & NS \\
Hypotensive episodes & $10 \pm 14$ & $7 \pm 12$ & NS \\
Cramps & $6 \pm 8$ & $7 \pm 7$ & NS
\end{tabular}

NS = Not significant

the low CD was excellent (table 1). Pre- and post-dialysis BP remained stable, and the prevalence of hypotensive episodes and cramps during the HD session did not change after the modification of CD. In a similar way, there was no modification in $\mathrm{BP}$ during the interdialytic period.

In conclusion, these results show that the reduction of $\mathrm{CD}$ from 3.5 to $2.5 \mathrm{mEq} / 1$ is well tolerated, without variations in BP or in the intradialysis symptoms. The intake of calcium supplements in our patients significantly increased during the study. It is possible that the administration of high doses of calcium carbonate favors a positive calcium mass balance with a significant contribution to cardiovascular stability.

\section{References}

1 Sperschneider G, Günther K, Marzoll I, Kirchner E, Stein G: Calcium carbonate $\left(\mathrm{CaCO}_{3}\right)$ : An efficient and safe phosphate binder in haemodialysis patients? A 3-year study. Nephrol Dial Transplant 1993;8:530-534.
2 Oettinger C, Oliver J, Macon E: The effects of calcium carbonate as the sole phosphate binder in combination with low calcium dialysate and calcitriol therapy in chronic hemodialysis patients. J Am Soc Nephrol 1992;3:995-1001.

3 Argiles A, Kerr P, Canaud B, Flavier JL, Mion $\mathrm{C}$ : Calcium kinetics and the long-term effects of lowering dialysate calcium concentration. Kidney Int 1993;43:630-640.

4 Zawada E, Bennet E, Stinson JB, Ramirez G: Serum calcium in blood pressure regulation during hemodialysis. Arch Intern Med 1981; 141:657-658.

5 Henrich WL, Hunt JM, Nixon JV: Increased ionized calcium and left ventricular contractility during hemodialysis. N Engl J Med 1984; 310:219-223.

6 Fabrizi E, Bacchini G, Di Filippo S, Pontoriero G, Locatelli F: Intradialytic calcium balances with different calcium dialysate levels. Nephron 1996;72:530-535.

7 Teruel JL, Navarro JF, Marcen R, Aguilera A, Tato A, Ortuño J: Satisfactory control of secondary hyperparathyroidism with low-calcium dialysate in patients not receiving vitamin D. Miner Electrolyte Metab 1997;23:19-24.

\section{KARGER}

Fax + 41613061234 E-Mail karger@karger.ch www. karger.com

\section{(C) 1998 S. Karger AG, Basel \\ 0028-2766/98/0781-0120\$15.00/0}

This article is also accessible online at: http://BioMedNet.com/karger
José L. Teruel, MD

Department of Nephrology, Hospital Ramón y Cajal

Carretera de Colmenar, Km 9.100

E-28034 Madrid (Spain)

Tel. +34 133688 19, Fax +3413368018 